\title{
Dynamic expression pattern and subcellular localization of the Rhox 10 homeobox transcription factor during early germ cell development
}

\author{
Hye-Won Song, Christina T Dann ${ }^{1}$, John R McCarrey ${ }^{2}$, Marvin L Meistrich $^{3}$, Gail A Cornwall ${ }^{4}$ and \\ Miles F Wilkinson \\ Department of Reproductive Medicine, School of Medicine, University of California, San Diego, 9500 Gilman Drive, \\ La Jolla, California 92093, USA, ${ }^{1}$ Department of Chemistry, Indiana University, Bloomington, Indiana, USA, \\ ${ }^{2}$ Department of Biology, University of Texas at San Antonio, San Antonio, Texas, USA, ${ }^{3}$ Department of Experimental \\ Radiation Oncology, The University of Texas MD Anderson Cancer Center, Houston, Texas, USA, ${ }^{4}$ Department of Cell \\ Biology and Biochemistry, Texas Tech University Health Science Center, Lubbock, Texas, USA
}

Correspondence should be addressed to M F Wilkinson; Email: mfwilkinson@ucsd.edu

\begin{abstract}
Homeobox genes encode transcription factors that regulate diverse developmental events. The largest known homeobox gene cluster the X-linked mouse reproductive homeobox (Rhox) cluster - harbors genes whose expression patterns and functions are largely unknown. Here, we report that a member of this cluster, Rhox10, is expressed in male germ cells. Rhox10 is highly transcribed in spermatogonia in vivo and is upregulated in response to the differentiation-inducing agent retinoic acid in vitro. Using a specific RHOX10 antiserum that we generated, we found that RHOX10 protein is selectively expressed in fetal gonocytes, germline stem cells, spermatogonia, and early spermatocytes. RHOX10 protein undergoes a dramatic shift in subcellular localization as germ cells progress from mitotically arrested gonocytes to mitotic spermatogonia and from mitotic spermatogonia to early meiotic spermatocytes, consistent with RHOX10 performing different functions in these stages.

Reproduction (2012) 143 611-624
\end{abstract}

\section{Introduction}

Homeobox genes encode transcription factors harboring a 60 amino acid DNA-binding domain known as a homeodomain (McGinnis \& Krumlauf 1992). Homeobox genes are present across the phylogenetic scale and have roles in a wide variety of events during embryonic development. Vertebrate species have more than 200 homeobox genes, which are grouped into subfamilies based on their sequence identity in the homeodomain. The best-known homeobox subfamily is the Hox subfamily, which contains family members that tend to be highly conserved in sequence, expression pattern, and function (Pearson et al. 2005). Hox family members direct diverse developmental steps during embryogenesis, including body axis patterning and cell specification (Krumlauf 1994). Likewise, members of other homeobox subfamilies are involved in various steps of embryonic development (Panganiban \& Rubenstein 2002).

While the role of homeobox genes in embryonic development has been well studied, very little is known about their expression patterns and roles in postnatal and adult developmental processes. One such developmental process is spermatogenesis, which initiates during postnatal development and continues in adulthood. While the organ where spermatogenesis takes place - the testis - expresses over 40 homeobox genes, their cellular sites of expression as well as their developmental expression pattern and functions are largely unknown (Maclean \& Wilkinson 2005).

The largest group of homeobox genes expressed in the \& Wilkinson testis is the reproductive homeobox (Rhox) genes, which, in mice, is comprised of 33 genes clustered together on the X chromosome (MacLean \& Wilkinson 2010). The mouse Rhox genes are grouped into three subclusters: $\alpha$ (Rhox 1 to Rhox 4 ), $\beta$ (Rhox 5 to Rhox9), and $\gamma$ (Rhox10 to Rhox13). There are eight paralogs of mouse Rhox2, Rhox3, and Rhox4, which probably arose as a result of a mouse-specific amplification of a trimer unit containing these three Rhox genes. The syntenic region of human and rat $\mathrm{X}$ chromosome also harbors a Rhox gene cluster, but with only three genes and 11 genes respectively (MacLean \& Wilkinson 2010). With the exception of mouse paralogs of the Rhox2, Rhox3, and Rhox4, Rhox genes have very little 
resemblance with each other outside of homeobox region, suggesting that each member has a unique function. To date, the only Rhox gene with a known function in vivo is Rhox 5 , which promotes germ cell survival during spermatogenesis and sperm maturation in the epididymis (Maclean et al. 2005).

While it has been clearly established that most of known Rhox genes from different mammalian species are expressed in the testis (MacLean \& Wilkinson 2010), in most cases, the cell types that express these genes in the testis is not known. This is not a trivial undertaking, as the testis contains a wide spectrum of germ cells at different developmental stages, as well as several different types of supporting somatic cells that change their gene expression profile when the adjacent germ cells undergo developmental advancement. In germ cells, X-linked genes are transcriptionally inactivated at the pachytene stage of meiosis by a process called meiotic sex chromosome inactivation (MSCl; Turner 2007). The existence of MSCI raised the possibility that $X$-linked genes, including all those in the Rhox gene cluster, are not expressed in germ cells, but rather in somatic cells in the testis. Indeed, the founding member of the Rhox gene cluster, Rhox 5, is specifically expressed in Sertoli cells, not germ cells, in postnatal and adult testes (Lindsey \& Wilkinson 1996, Rao et al. 2003). However, there is growing evidence that many X-linked genes are expressed in germ cells. In fact, it has been reported that spermatogonia-specific genes are overrepresented on the $X$ chromosome (Wang et al. 2001). Most of these genes, including the Rhox13 gene, are expressed in germ cells at a developmental stage before $\mathrm{MSCl}$ takes place, i.e. dividing spermatogonia or early spermatocytes (Geyer \& Eddy 2008, Zheng et al. 2010). Other germ cell genes are expressed in postmeiotic germ cells after $\mathrm{MSCl}$ is no longer operative (Mueller et al. 2008, Yang et al. 2008).

In this paper, we focus on the Rhox 10 gene, a member of the mouse Rhox $\gamma$ subcluster. Rhox10 is a putative ortholog of the human RHOXF1 gene, based on their sequence identity (ensembl.org). We have previously reported that Rhox 10 mRNA is expressed in adult mouse testes, epididymis, placenta, and ovary but is not detectable in 18 other adult mouse organs, as assessed using quantitative RT-PCR analysis (Maclean et al. 2005). This selective expression pattern indicated that the Rhox 10 gene is specifically transcribed in reproductive tissues. Here, we provide a detailed analysis of the expression pattern of Rhox10 in the male reproductive tract, with a focus on the testis. We provide several lines of evidence that $R$ hox 10 is selectively transcribed in germ cells and that it is most highly expressed in premeiotic germ cells. Likewise, we show that RHOX10 protein is selectively expressed in premeiotic and early meiotic germ cells in fetal, postnatal, and adult testis. We elucidate the developmental pattern of Rhox10 mRNA and RHOX10 protein expression during the first wave of spermatogenesis and show that there is a dramatic shift in the subcellular localization of RHOX10 protein at specific stages of germ cell development in the adult testis. Together, our data suggest that Rhox10 is a transcriptional regulator that, in turn, is regulated at both the transcriptional and the posttranscriptional levels in response to specific developmental cues in male germ cells.

\section{Results \\ Expression pattern of Rhox10 mRNA and RHOX10 protein during the first wave of spermatogenesis}

To elucidate the expression pattern and localization of the RHOX10 protein, we generated an antiserum against mouse RHOX10 in rabbits. For an immunogen, we chose the N-terminal half of RHOX10, as this lacks the homeobox region, which, if included, would likely generate cross-reacting antibodies that bind to other homeobox proteins. Western blot analysis revealed that the RHOX10 antiserum detected a $\sim 25 \mathrm{kDa}$ doublet in mouse testes (Fig. 1A, lane 7), a size closely matching its predicted molecular weight of $22.7 \mathrm{kDa}$. In addition to its size, several lines of experimental evidence supported the notion that the $\sim 25 \mathrm{kDa}$ doublet is RHOX10: i) its level is higher in postnatal testes than in adult testes (Fig. 1A, compare lanes 7 and 8), which is consistent with the expression pattern of Rhox10 mRNA (see below); ii) it was not detectably present in liver and brain (lanes 9 and 10, respectively, in Fig. 1A), neither of which detectably express Rhox 10 mRNA (Maclean et al. 2005); iii) it was highly expressed in HeLa cells transfected with a Rhox10 expression vector (Fig. 1A, lane 11); iv) this expression was drastically reduced when these cells were cotransfected with a Rhox10 shRNA vector (Fig. 1A, lane 12); and v) preincubation with recombinant GST-RHOX10 protein drastically reduced the level of the $\sim 25 \mathrm{kDa}$ doublet (red boxes in Fig. 1A) but not other (nonspecific) bands (marked with a $\left(^{*}\right)$ in Fig. 1A).

We used this antiserum to determine the expression pattern of RHOX10 protein during the first wave of spermatogenesis by western blot analysis (Fig. 1B and C). This revealed that RHOX10 is present in the testes at the earliest time point we examined (postnatal (P) day 3 ). RHOX10 protein levels increase between $\mathrm{P} 3$ and $\mathrm{P9}$, the time window when spermatogonia undergo expansion. Its expression gradually declines after P10, when spermatogonia decline in number as a result of their conversion into meiotic spermatocytes.

Using qRT-PCR analysis, we determined the temporal pattern of Rhox10 mRNA during the first wave of spermatogenesis (Fig. 1D). This analysis revealed that Rhox10 mRNA has a similar temporal pattern of expression as that of RHOX10 protein, suggesting that RHOX10 translation is not significantly regulated during postnatal testes development. Of note, we found that Rhox10 mRNA is dramatically upregulated between 
P5 and P7 (Fig. 1C), which coincides with the expansion of spermatogonia in the testis. This result, along with the upregulation of RHOX10 protein during the same time window raises the possibility that RHOX10 is expressed in spermatogonia, a possibility that we examine in the following sections.

\section{Cell type-specific expression of Rhox10 mRNA in the testis}

To examine the cell type(s) in the testes that express Rhox10, we took two approaches. First, we examined the expression of Rhox10 in three germ cell-deficient mouse models: i) a mouse model of Klinefelter's syndrome (KS) that has a XXY karyotype and virtually lack all germ cells in the adult testis (Swerdloff et al. 2011);

A

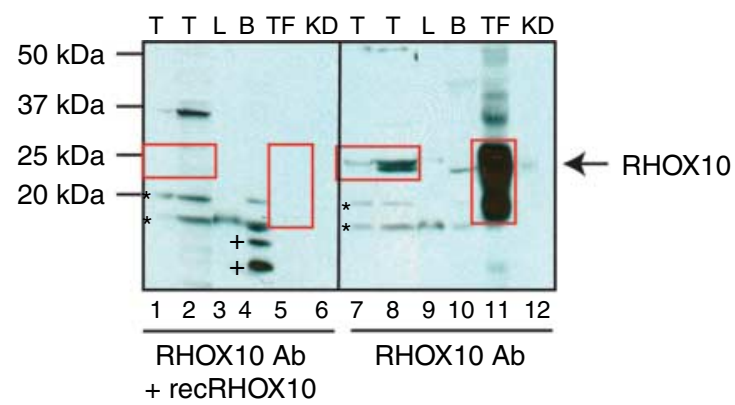

B
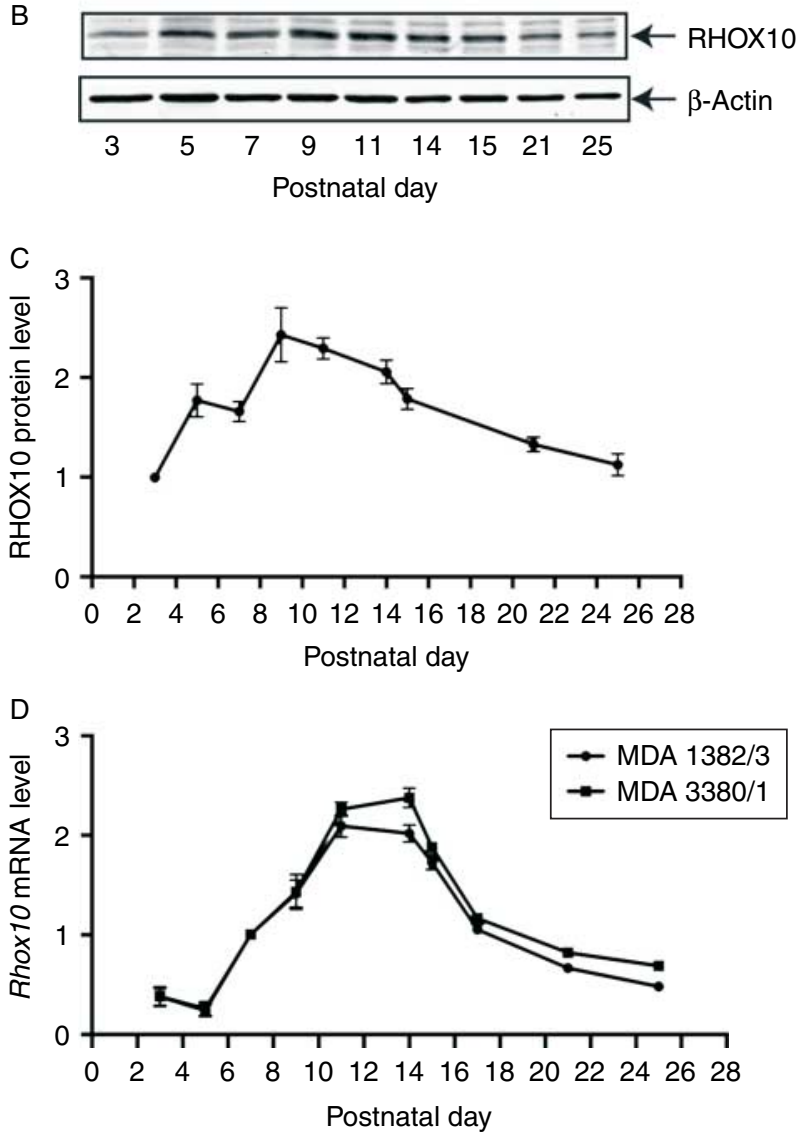

ii) irradiated wild-type mice, which lose spermatogonial stem cells (SSCs) and thus contain only somatic cells 5 weeks after irradiation (Zhang et al. 2006); and iii) juvenile spermatogonial depletion $(j s d)$ mice, which lack all germ cells in adult testes except for undifferentiated type $A$ spermatogonia $\left(A_{s}, A_{p r}\right.$ and $A_{a l}$ spermatogonia) (de Rooij et al. 1999). Using qRT-PCR analysis, we found that testes from adult KS mice had nearly undetectable levels of Rhox 10 mRNA (Fig. 2A). Confirmation that germ cells were depleted was the finding that the germ cell markers - Dazl, Stra8, Nanos2, and/or Neurog3 (Ngn3) - were reduced in level, while the Sertoli cell markers - Gata1 and/or Tubb3 - were enriched (Fig. 2A). Essentially the same results were observed in germ cell-depleted testes from irradiated mice (Fig. 2B). In contrast, adult jsd testes, which still contain undifferentiated type A spermatogonia (de Rooij et al. 1999), had high levels of Rhox10 mRNA (Fig. 2C). We confirmed the expected phenotype of the adult $j s d$ testes, as we found that they expressed the spermatogonial markers Nanos2 and Neurog3 but had low levels of the later stage germ cell markers Stra8 and DazI (Fig. 2C). Together, these results indicate that Rhox 10 is primarily expressed in premeiotic male germ cells in the adult testes, including undifferentiated type A spermatogonia.

As a second approach, we assayed Rhox 10 mRNA levels in highly purified germ cell subsets at different stages of maturity, generated as described previously (Yoshioka et al. 2007). qRT-PCR analysis revealed that Rhox 10 was most highly expressed in the earliest germ cell subset: undifferentiated type A spermatogonia (Fig. 3A). This agrees with our findings, described earlier,

Figure 1 Temporal expression pattern of Rhox 10 mRNA and RHOX10 protein. (A) Western blot analysis to validate the specificity of the RHOX10 antiserum (labeled 'RHOX10 Ab'). The left blot was preincubated with recombinant GST-RHOX10 protein before being probed with the RHOX10 antiserum. T, P12 (left) and adult (right) testes; L, liver; B, brain; TF, HeLa cells transfected with a Rhox 10 expression vector (see Materials and Methods section); KD, HeLa cells cotransfected with both the Rhox 10 expression vector and a Rhox 10 shRNA vector. The red box encloses bands that represent RHOX10, based on the finding that they largely disappeared when the blot was preincubated with GST-RHOX10. *Nonspecific bands detected in both blots. + Nonspecific bands that appeared in response to GST-RHOX10 preincubation. (B) Western blot analysis of testis lysates from postnatal mice of the ages indicated below each lane. $\beta$-Actin is the loading control. (C) The relative level of RHOX10 protein in postnatal testes determined by western blot analysis using an infrared-labeled secondary antibody detected by the Odyssey system, which provides linear quantification of protein levels over a 4000 -fold range. RHOX10 protein levels were determined by normalization to the level of $\beta$-actin protein (the level at P3 was arbitrarily set to 1). At least two mice were used per time point. Values denote the mean fold change \pm s.E.M. (D) Rhox 10 mRNA levels in postnatal testes determined by qRT-PCR analysis using the two independent primer pairs indicated. At least two mice were used per time point. Rhox 10 mRNA levels were determined by normalization against the mRNA encoding the ribosomal protein RPL19 (Rhox10 mRNA level at P7 was arbitrarily set to 1). Values denote the mean fold change \pm s.E.M. 
that i) Rhox 10 is highly expressed in testes from jsd mice (Fig. 2C), which are enriched for undifferentiated type A spermatogonia (de Rooij et al. 1999), while ii) little or no Rhox10 mRNA is expressed in testes from KS and irradiated mice (Fig. 2A and B), which lack undifferentiated type A spermatogonia. As further support, Rhox10 is also highly expressed in germline stem (GS) cell cultures, as described later.

Rhox 10 mRNA level progressively declined in level in postmeiotic germ cell subsets (Fig. 3A), which is consistent with the finding that Rhox10 mRNA and RHOX10 protein expression peaks during postnatal
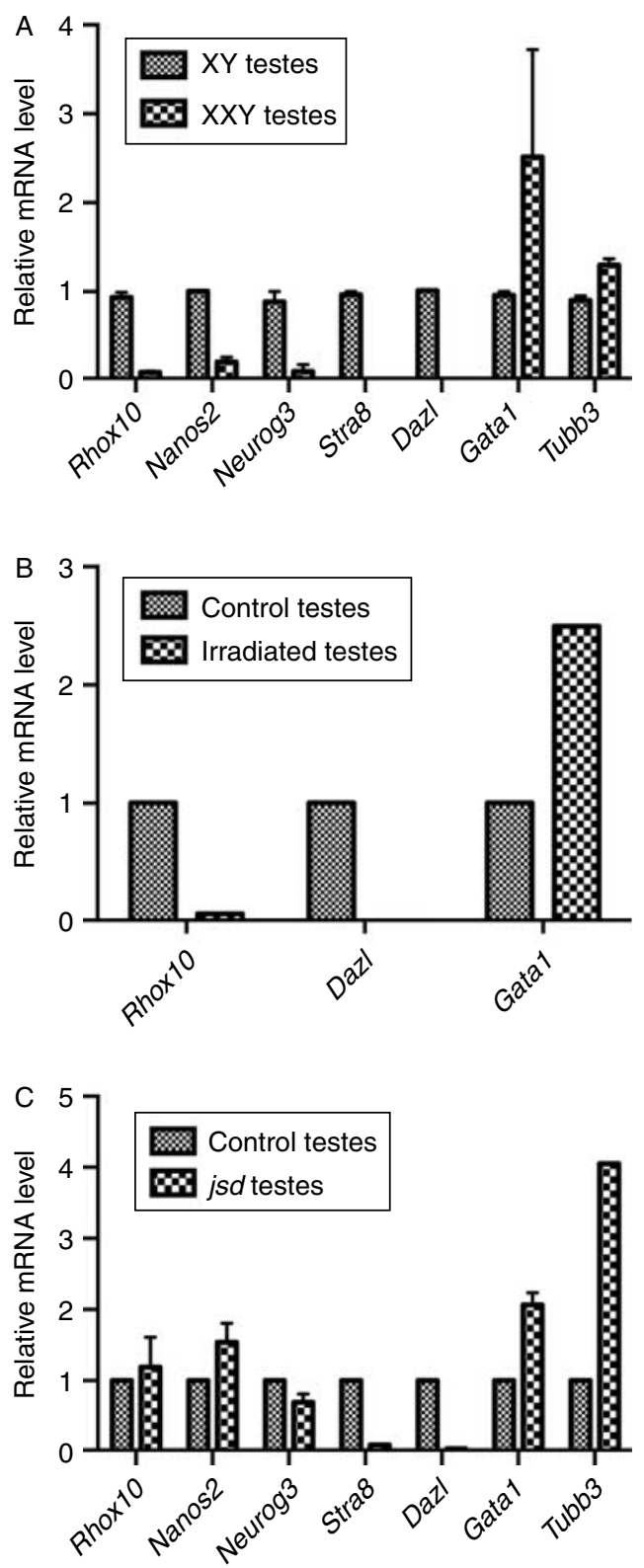

Figure 2 Rhox 10 expression in germ cell-deficient testes. qRT-PCR analysis of testes from $X X Y(A)$, irradiated $(B)$, and $j s d(C)$ adult mice, along with littermate control mice, performed and quantified as in Fig. 1. The level of the indicated mRNAs in control testes was arbitrarily set to 1. development when premeiotic germ cell subsets predominate (Fig. 1). This expression pattern suggests that RHOX10 is a good candidate to have functional roles in spermatogonia and early spermatocytes. However, because some Rhox10 mRNA is present even in highly purified late spermatocytes, round spermatids, and elongated spermatids (Fig. 3A), we cannot rule out that it has roles in later germ cell events as well.

\section{Transcriptional control of Rhox10}

As Rhox10 is on the X chromosome, it would be expected to undergo $\mathrm{MSCl}$, a process that leads to the transcriptional inactivation of genes on sex chromosomes when meiotic synapsis of autosomes is complete, shortly after the zygotene-to-pachytene transition (Turner 2007). MSCl is generally believed to be an 'absolute' process, as there have been no reports of X-linked protein-coding gene escaping the silencing effect of $\mathrm{MSCl}$. However, recent evidence suggests that a group of $\mathrm{X}$-linked micro-RNA genes escape $\mathrm{MSCl}$ (Song et al. 2009), so we considered the possibility that Rhox10 escapes MSCl. Consistent with this, we observed that Rhox 10 mRNA is present at relatively high levels in the germ cell subset that undergoes $\mathrm{MSCl}$ : pachytene spermatocytes. Indeed, Rhox 10 mRNA levels are only approximately threefold less in pachytene spermatocytes than in undifferentiated type A spermatogonia, the germ cell type that expresses the highest level of Rhox10 (Fig. 3A). To test whether Rhox10 escapes MSCl, we assayed Rhox 10 pre-mRNA level, as several studies have used pre-mRNA levels as a reliable measure of gene transcription rate (Imam et al. 2009, Huang et al. 2011). qRT-PCR analysis revealed that while Rhox 10 pre-mRNA is extremely high in both undifferentiated type A spermatogonia and differentiating type A spermatogonia (type $A_{1-4}$ spermatogonia), its level drops sharply in all the more mature germ cell subsets, including pachytene spermatocytes, where $\mathrm{MSCl}$ occurs (Fig. 3B). For controls, we examined the X-linked gene Fmr1 and the autosomal gene Upf3a, the latter of which has an X-linked paralog, Upf3b (Chan et al. 2009). Consistent with its control by $\mathrm{MSCl}$, Fmr1 levels were very low in pachytene spermatocytes (Fig. 3C), whereas the Upf3a autosomal gene was highly expressed in pachytene spermatocytes (Fig. 3D). Together, these data strongly suggest that Rhox10, like all known protein-coding $\mathrm{X}$-linked genes, is subject to MSCl.

\section{Dynamic developmental regulation and subcellular localization of RHOX10 protein in germ cells}

To determine which testicular cell type(s) expresses RHOX10 protein, we performed immunohistochemical analysis on adult testis sections using the specific RHOX10 antiserum that we generated. As detailed 

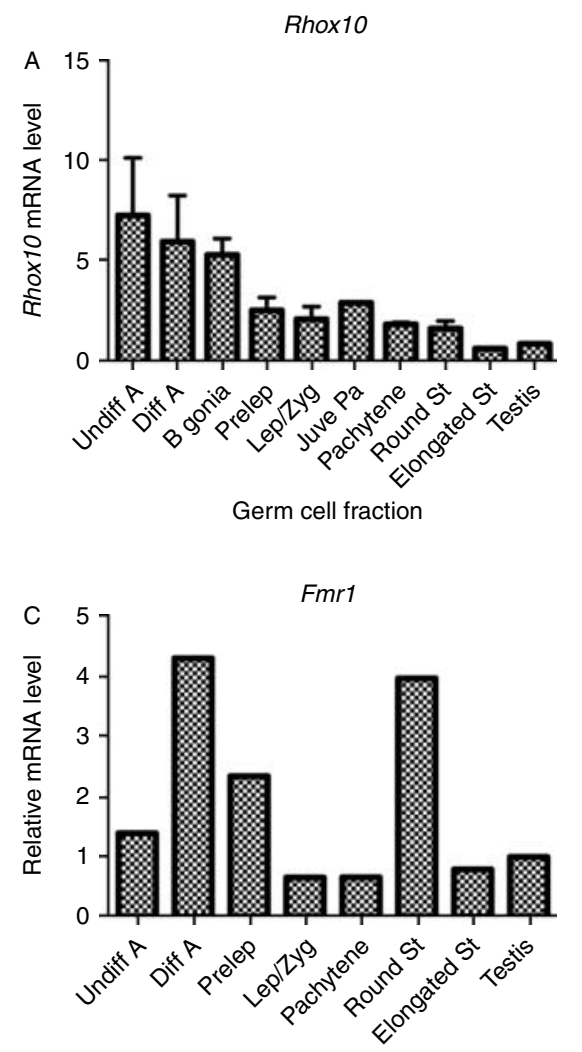

Germ cell fraction
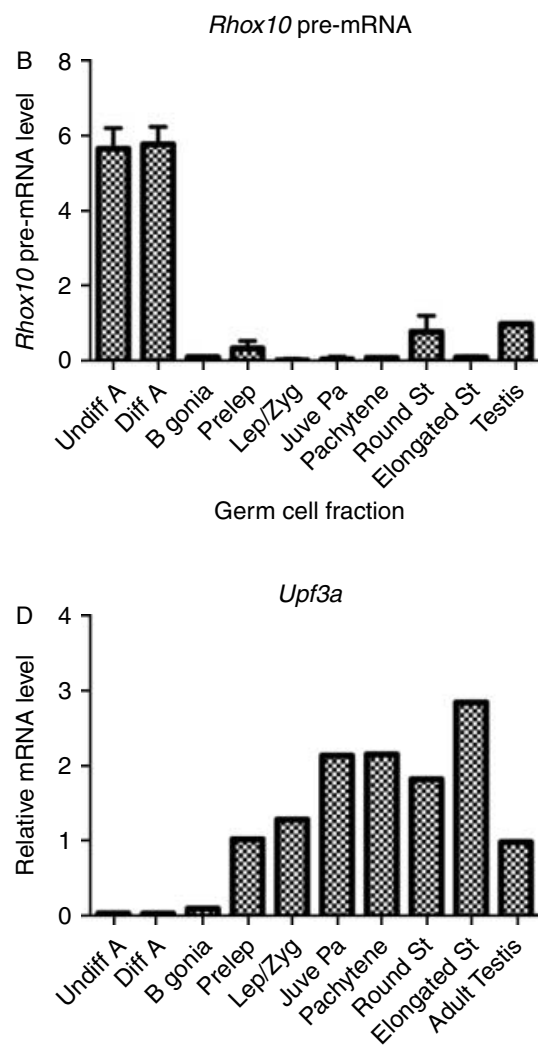

Germ cell fraction
Figure 3 Rhox10 is most highly expressed in immature germ cells. qRT-PCR analysis of Rhox10 mature mRNA level (A), pre-mRNA level (B), Fmr1 (X-linked) mRNA level (C), and Upf3a (autosomal) mRNA level (D) determined in nine mouse male germ cell fractions and adult testes, performed and quantified as in Fig. 1. The level of each mRNA in adult testes was arbitrarily set to 1 . Undiff $A$, undifferentiated type $A$ spermatogonia $\left(A_{s}, A_{p r}\right.$ and $\left.A_{a l}\right)$; Diff $A$, differentiating type $A$ spermatogonia $\left(A_{1}, 2,3,4\right)$; $B$ gonia, type $B$ spermatogonia; Prelep, preleptotene spermatocytes; Lep/Zyg, leptotene and zygotene spermatocytes; Juve Pa, early (juvenile) pachytene spermatocytes; Pachytene, pachytene spermatocytes; Round St, round spermatids; Elongated St, elongated spermatids and residual bodies. earlier, this RHOX10 antiserum displays specificity for the RHOX10 protein, based on several lines of evidence (Fig. 1A). Further evidence for its specificity is that preincubation with recombinant GST-RHOX10 protein resulted in a drastic reduction of staining with the RHOX10 antiserum (Fig. 4A). We found that this RHOX10 antiserum stained germ cells (strongly so at some developmental stages) but did not detectably stain somatic testicular cells (e.g. Sertoli, Leydig, and myoid cells) (Fig. 4). As described in detail below, this antiserum detected RHOX10 protein in premeiotic and early meiotic germ cell subsets (spermatogonia and early spermatocytes) but not in later meiotic and haploid germ cell subsets (diplotene spermatocytes, round spermatids, and elongated spermatids).

We elucidated the precise developmental stages of spermatogonia and spermatocyes that express RHOX10 by examining testis tubules at different stages of the seminiferous epithelial cycle. The tubule stages were determined by the specific cohort of spermatogenic cell types observed in adjacent sections stained with periodic acid Schiff (PAS) and hematoxylin. In stages II to IV seminiferous tubules - which were characterized by having round spermatids with round or slightly flat acrosomes stained with PAS (Fig. 4B, insets) - we observed staining with the RHOX10 antiserum in both the nuclei and the cytoplasm of the type $A$ and intermediate spermatogonia (Fig. 4B, arrows). RHOX10 staining was also observed in the nuclei of the early pachytene spermatocytes that are also present in these tubule stages (Fig. 4B, arrowheads). In stage $\mathrm{V}$ to $\mathrm{VI}$ tubules - which were characterized by having round spermatids with acrosomes subtended by an angle of $40^{\circ}-120^{\circ}$ (Fig. 4C, insets) - we observed RHOX10 staining in both the nuclei and cytoplasm of the type B spermatogonia present in these stages (Fig. 4C, arrows). Unlike early pachytene spermatocytes in stages II to IV, stage $\mathrm{V}$ to $\mathrm{VI}$ pachytene spermatocytes did not have detectable RHOX10 staining in the nuclei but instead had modest levels of RHOX10 staining in the cytoplasm (compare Fig. 4B and C, arrowheads). In stage VIII tubules, RHOX10 staining was detected in the nuclei and cytoplasm of the type A spermatogonia (Fig. 4D, double arrow), the nuclei of preleptotene spermatocytes (Fig. 4D, arrows), and at modest levels in the cytoplasm of the late pachytene spermatocytes present at this stage (Fig. 4D, arrowheads). At stage IX, RHOX10 staining was high in the nuclei of the leptotene spermatocytes (Fig. 4E, arrows) and very modest in the cytoplasm of late pachytene spermatocytes (Fig. 4E, arrowheads). Finally, analysis of stage $\mathrm{XI}$ seminiferous tubules revealed that RHOX10 staining was in both the nuclei and the cytoplasm of type $A$ spermatogonia $\left(A_{2}-A_{3}\right)$ (Fig. 4F, double arrows) and in the nuclei of zygotene 

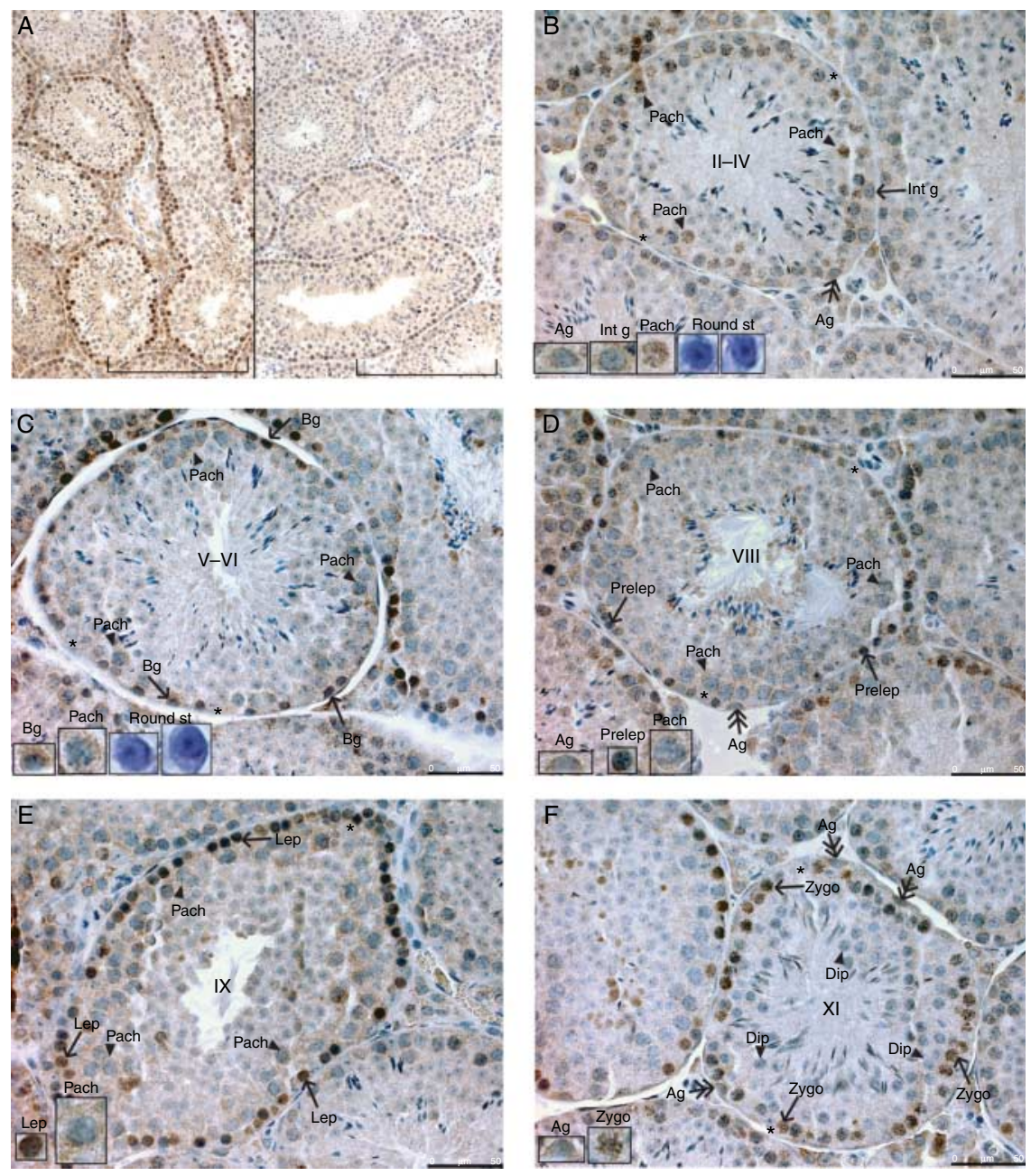

Figure 4 Dynamic RHOX10 localization and expression pattern. Immunohistochemical analysis performed on adult testis sections with RHOX10 antiserum (A-left, B, C, D, E and F) and with RHOX10 antiserum after RHOX10-GST preincubation (A-right). Brown staining indicates RHOX10 antiserum reactivity; nuclei are stained blue with hematoxylin counterstain. *Sertoli cell nuclei. Tubule stages are indicated in roman numbers. Enlarged views of RHOX10-stained cells and periodic acid Schiff (PAS)-hematoxylin-stained cells are shown in the inset boxes. Ag, type $A$ spermatogonia; Int g, Intermediate spermatogonia; Bg, type B spermatogonia; Prelep, preleptotene spermatocytes; Lep, leptotene spermatocytes; Zygo, zygotene spermatocytes; Pach, pachytene spermatocytes; Dip, diplotene spermatocytes. (A) Scale bar: $200 \mu \mathrm{m}$. (B, C, D, E and F) Scale bars: $50 \mu \mathrm{m}$. spermatocytes (Fig. 4F, arrows). There was no detectable staining in the diplotene spermatocytes present at this stage (Fig. 4F, arrowheads). In summary, immunohistochemical analysis indicated that RHOX10 is expressed at all spermatogonial stages we examined (type A, intermediate, and type B) and in most stages of spermatocytes (preleptotene, leptotene, zygotene, and pachytene).

\section{Region-specific expression of RHOX10 in the epididymis}

To explore whether RHOX10 is exclusively expressed in germ cells, we turned to the epididymis, the only other tissue in adult male mice that expresses the Rhox10 gene, according to our previous qRT-PCR analysis of 18 adult tissues (MacLean et al. 2005). The epididymis is divided into three regions - the caput, the corpus, and the cauda - each of which expresses distinct subsets of genes and has distinct functions, including promotion of sperm maturation and protection from oxidative damage (Cornwall 2009). These three regions are further subdivided into smaller segments that are separated by physical boundaries (Fig. 5A). Each segment expresses distinct sets of genes that permit each segment to harbor luminal fluid with different contents, which, in turn, may endow each segment with distinct functional properties (Turner et al. 2003, Cornwall 2009). To examine whether RHOX10 protein is expressed in the epididymis, we performed immunohistochemical analysis on adult epididymis sections with the RHOX10 antiserum. This revealed high levels of RHOX10 staining confined to epithelial cells in the caput region (primarily in segments 2 and 3, with lower levels in segment 1) (Fig. 5B). We did not observe significant staining in the corpus and cauda regions (data not shown). This caput-specific staining was abolished by preincubation with recombinant GSTRHOX10 protein, indicating that the staining was the result of Rhox 10 expression (Fig. 5E and F). RHOX10 was only detectable in epithelial cells in the caput, where it accumulated in both the nucleus and the cytoplasm (Fig. 5C, arrows). No RHOX10 was detectable in the epididymal germ cells (i.e. the spermatozoa) or the epididymal myoid cells (Fig. 5C, double arrows). 
A

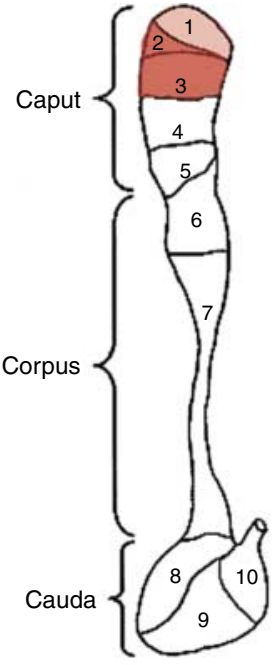

B

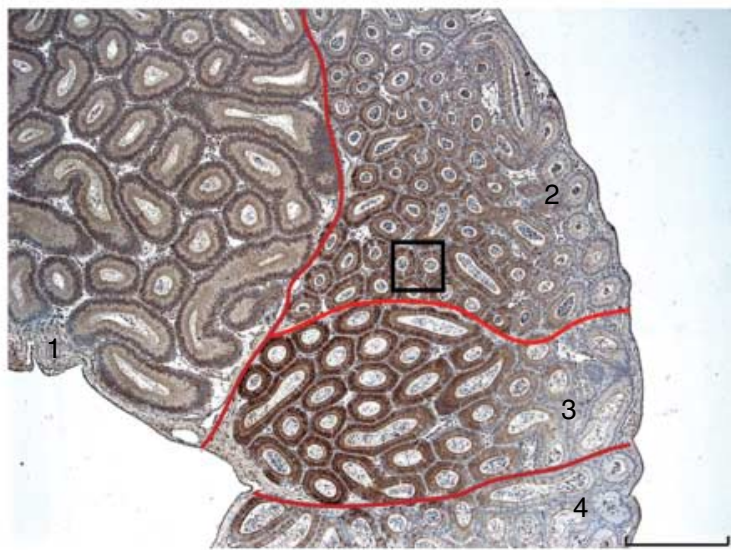

C

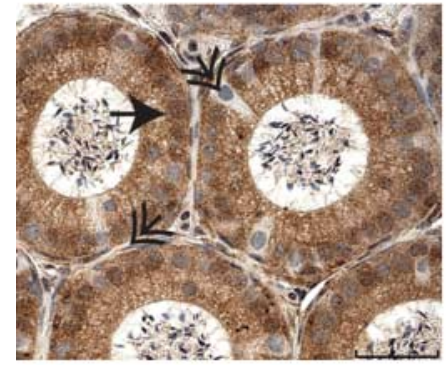

E

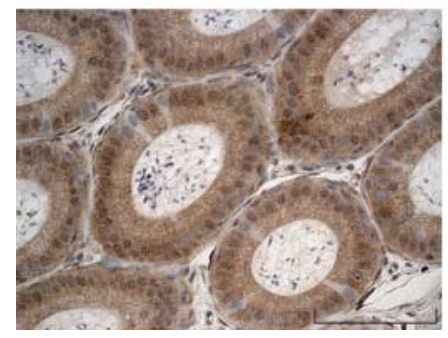

D

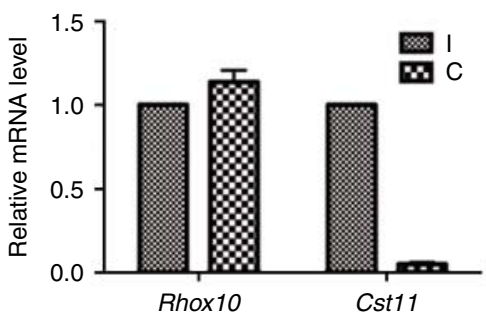

F

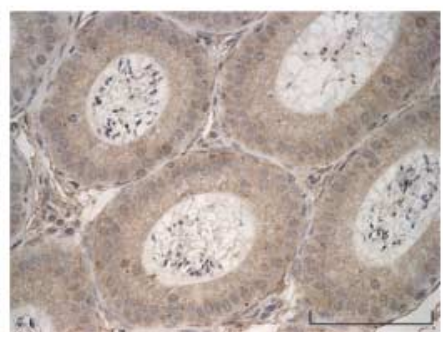

Figure 5 RHOX10 is expressed in somatic cells in the epididymis. (A) Schematic showing the expression pattern of RHOX10 protein in different segments of the epididymis. (B) Immunohistochemical analysis of an adult epididymis section, performed with the RHOX10 antiserum, showing that RHOX10 is highly expressed in segments 2 and 3 of the caput region (brown stain).

Nuclei are stained blue with hematoxylin counterstain. Red lines indicate the position of septula, the connective tissue that divides segments. Scale bar: $400 \mu \mathrm{m}$. (C) Enlarged view of inset box in panel B. Single- and double-headed arrows point to epididymal cells positive and negative for RHOX10 respectively. Scale bar: $25 \mu \mathrm{m}$. (D) qRT-PCR analysis on unilaterally castrated (C) and intact (I) epididymides, performed and quantified as in Fig. 1. The level of the indicated mRNAs in intact epididymides was arbitrarily set to 1 . ( $E$ and F) Immunohistochemical analysis of an adult caput epididymis section, performed with the RHOX10 antiserum and with RHOX10 antiserum after RHOX10-GST preincubation respectively. Scale bars: $200 \mu \mathrm{m}$.
RHOX10 protein exhibited a mosaic pattern of expression in the caput, as some epithelial cells in the caput had low or undetectable levels of RHOX10 (Fig. 5C, double arrows).

The expression of many genes in the epididymis depends on testicular factors traveling through the luminal fluid from the efferent ducts (Turner et al. 2003, Cornwall 2009). To test whether this was the case for Rhox10, we performed a unilateral castration experiment, which prevents testicular factors from entering the epididymis on one side while the other side is left intact. This treatment dramatically reduced the level (by $\geq 95 \%$ ) of a previously identified testicular factor-regulated gene, Cst11 (Cres2) (Cornwall et al. 1992, Hsia \& Cornwall 2003), but did not significantly affect Rhox10 mRNA levels (Fig. 5D). We conclude that the expression of Rhox10 in the epididymis is achieved without the requirement for luminal testicular factors.

\section{Fetal germ cells express RHOX10 in the cytoplasm}

Given that RHOX10 is present in spermatogonia in the adult testis, we examined whether it is also present in gonocytes in the fetal testis. First, we examined RHOX10 protein expression by immunohistochemical analysis of E15.5 male fetal testes. This analysis revealed that most gonocytes stained with the RHOX10 antiserum (Fig. 6A). Their identity as gonocytes was confirmed by their staining with the fetal germ cell marker POU5F1 (Fig. 6B). We only observed RHOX10 protein in the cytoplasm but not in the nucleus of gonocytes (Fig. 6A). As a control for antibody specificity, we tested preimmune $\lg G$ and found that it did not elicit significant staining (Fig. 6C and D). Rhox10 expression was restricted to the gonocytes; we detected no RHOX10 staining in the adjacent somatic cells. Secondly, we examined Rhox 10 expression at the mRNA level in fetal and early postnatal testes. As a control, we also 


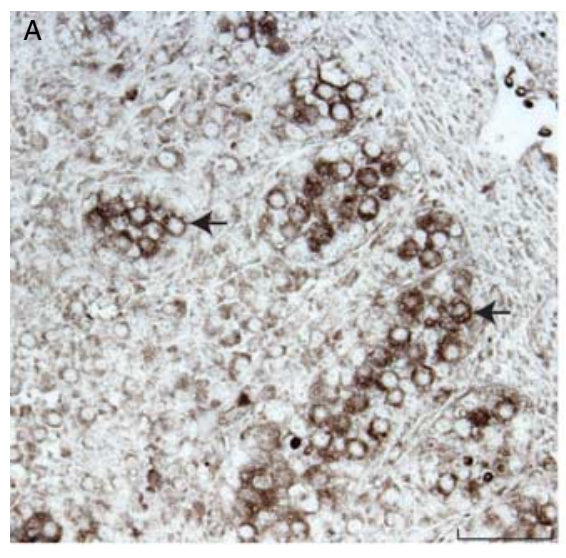

$\mathrm{RHOX} 10 \mathrm{Ab}$

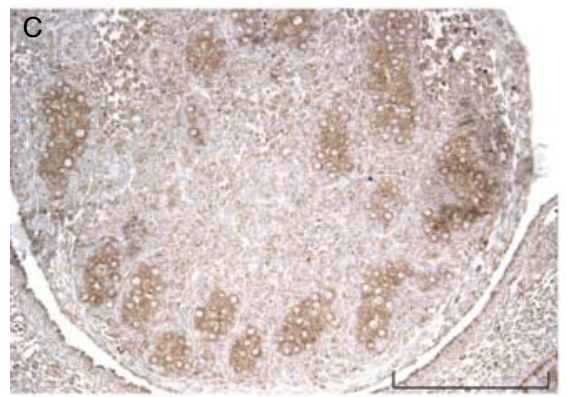

$\mathrm{RHOX} 10 \mathrm{Ab}$

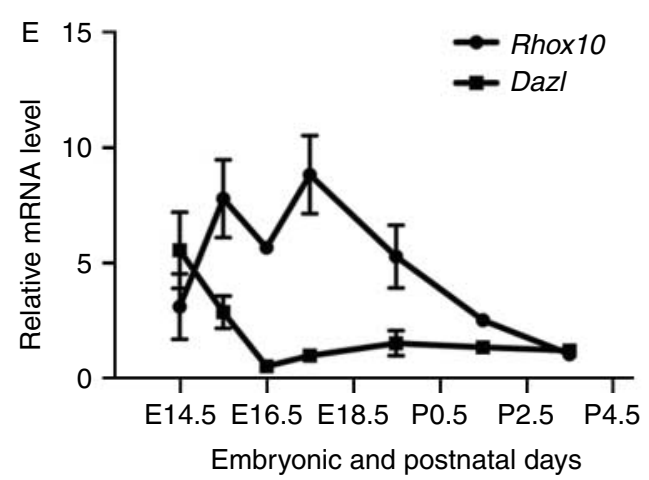

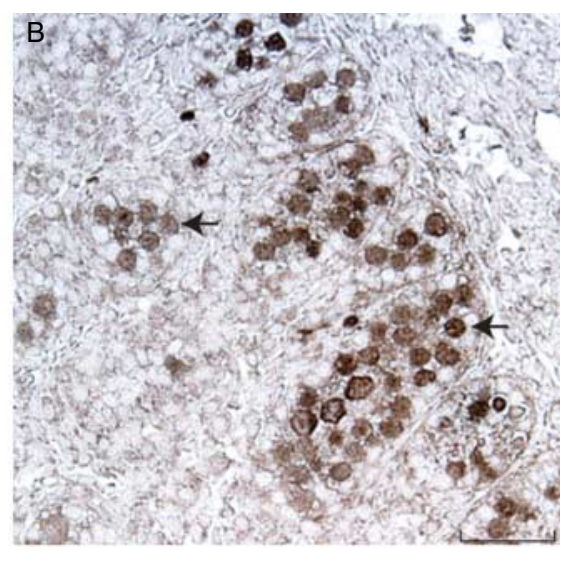

POU5F1 Ab

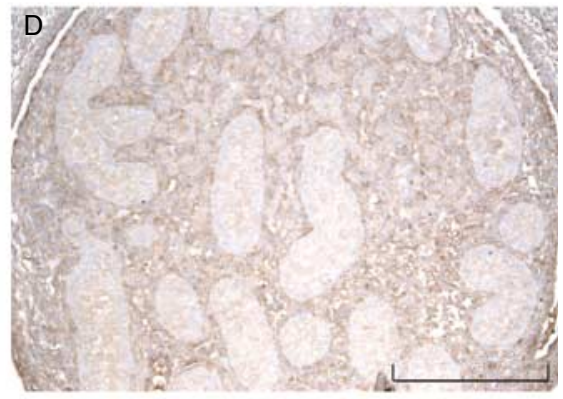

$\lg G$

Figure 6 RHOX10 is expressed in gonocytes. (A, B, C and D) Immunohistochemical analysis performed with the antiserum indicated on E15.5 male fetal gonad sections. (A and B) The data show serial sections probed with the two antisera shown. The data indicate that most gonocytes (the POU5F1-positive cells) express RHOX10 (the arrows point to two examples of double-stained gonocytes). Scale bar: $50 \mu \mathrm{m}$. (C and D) Scale bar: $100 \mu \mathrm{m}$. (E) qRT-PCR analysis of Rhox 10 and Dazl mRNA level in fetal testes and postnatal testes, performed and quantified as in Fig. 1. The level of mRNA in P3 testes was arbitrarily set to 1 .

examined the germ cell-specific marker Dazl. We found that Dazl mRNA level dramatically decreases during the period we examined (from embryonic (E) 14.5 until P3; Fig. 6E). Because this is a period when most germ cells are not proliferating, whereas somatic cells in the testis are proliferating, this decrease in Dazl level is most likely the result of a reduced ratio of germ cells to somatic cells. In contrast, we found that Rhox10 mRNA expression peaks at E15.5-17.5 and gradually decreases until P3 (Fig. 6E). The decrease in Rhox 10 mRNA level in late fetal/early postnatal testes is probably at least partly the result of a reduction in germ cells. These data are consistent with the finding of Sinclair and colleagues, who observed that Rhox10 mRNA was present in purified fetal germ cells but not in purified fetal somatic cells, obtained by fluorescence-activated cell sorting
(Daggag et al. 2008). These investigators also made the intriguing observation that Rhox10 is unique among all Rhox genes in being expressed specifically in male fetal germ cells. Other Rhox genes are either expressed in both male and female germ cells, only in female germ cells, or are not detectably expressed in fetal germ cells (Daggag et al. 2008).

\section{Expression and regulation of Rhox10 in GS cells}

Functional analysis of germ cell-specific genes has traditionally been a challenge as a reliable in vitro germ cell culture system has not been available. However, recently, several groups have developed methods to culture germ cells. These GS cells, which are generated from postnatal testes, are enriched in SSCs 
(Kubota et al. 2004, Kanatsu-Shinohara \& Shinohara 2007). The high levels of Rhox 10 mRNA in undifferentiated type A spermatogonia (Fig. 3A) led us to test whether Rhox10 is also expressed in GS cells. Using qRT-PCR, we found that GS cells express high levels of Rhox 10 mRNA, comparable with their level in postnatal testes (Fig. 7A). Immunofluorescence analysis demonstrated that RHOX10 protein is expressed in most of the cells in GS cultures (Fig. 7B). Both the nucleus and the cytoplasm of the GS cells accumulated RHOX10 protein (Fig. 7B), consistent with what we observed in spermatogonia in vivo (Fig. 4).

To determine whether Rhox10 is regulated by differentiation cues in spermatogonial cells, we treated GS cells with retinoic acid (RA), a known inducer of germ cell meiosis (Bowles et al. 2006, Anderson et al. 2008, Griswold et al. 2012). We found that RA treatment for $24 \mathrm{~h}$ dramatically increased Rhox 10 mRNA level (Fig. 7C). The induction was transient, as Rhox $10 \mathrm{mRNA}$ returned to pretreatment levels after $72 \mathrm{~h}$ of $\mathrm{RA}$ treatment. As a positive control for differentiation, we examined the expression of the stimulated by RA gene- 8 (Stra8) gene, which is upregulated in GS cells undergoing RA-induced differentiation in vitro and is highly expressed in differentiating type A spermatogonia in vivo (Dann et al. 2008). We found that Stra8 mRNA expression was increased $>200$-fold in GS cells after RA treatment. As a positive control for loss of stem cells, we examined the stem cell marker, Pou5f1 (also known as Oct4), and found it decreased in level upon RA treatment, in agreement with previous studies (Dann et al. 2008). Finally, the germ cell marker, Dazl, served as a control germ cell transcript whose expression is not significantly altered in response to differentiation cues (Dai et al. 2001).

\section{Discussion}

Although there are up to $\sim 20000$ different transcripts expressed in a given cell type, most of them are ubiquitously expressed housekeeping genes; only a few key genes are typically responsible for the specific activities in a particular cell type (Zhang et al. 1997). It is crucial to regulate these key genes at specific times and places, a process that is mediated, in part, by developmentally regulated and cell type-specific transcription factors. In this communication, we demonstrate that a member of the RHOX transcription factor family - RHOX10 - is expressed in germ cells in prenatal and postnatal testes in a developmentally regulated manner. We provide several lines of evidence that the expression of the Rhox 10 gene is transcriptionally and posttranscriptionally regulated in male germ cells within the testis (Figs 2 and 3). RHOX10 is also regulated at the protein level, as our immunohistochemical analysis indicated that the subcellular localization of RHOX10 protein is controlled in developmentally regulated manner (Figs 4, 5, 6 and 8).

The developmentally regulated shifts in RHOX10 subcellular localization during male germ cell development are summarized in Fig. 8. RHOX10 is exclusively present in the cytoplasm of mitotically arrested gonocytes in the fetal gonad. After birth - in premeiotic germ cells (spermatogonia) - RHOX10 is in both the cytoplasmic and the nuclear compartments. In leptotene spermatocytes, RHOX10 is no longer detectable in the cytoplasm, suggesting the existence of a switch that restricts RHOX10 to the nucleus at this meiotic stage. Zygotene and early pachytene spermatocytes maintain this nuclearspecific localization pattern. However, after the midpachytene transition, late pachytene spermatocytes lose detectable expression of RHOX10 in the nucleus and appear to acquire low levels of RHOX10 in the cytoplasm. This suggests the existence of a second subcellular switching mechanism at this stage. By analogy, another germ cell protein, STRA8, shuttles between nucleus and cytoplasm in a developmentally regulated manner. Evidence has been obtained that the nuclear localization signal and nuclear export signal in STRA8 are critical for these shifts in localization (Tedesco et al. 2009).

The localization of RHOX10 in not only the nucleus but also in the cytoplasm was unexpected given that transcription factors typically only have a role in the former cellular compartment. Indeed, another RHOX family member - RHOX 5 - is found exclusively in the nucleus of all cell types that have been examined, where it regulates the expression of a variety of target genes (Lindsey \& Wilkinson 1996, Rao et al. 2003, Hu et al. 2010). In the case of RHOX10, it is present in the nucleus in spermatogonia and early spermatocytes, suggesting the possibility that it regulates target genes in the nucleus at these stages that influence mitosis and meiosis respectively. But why is RHOX10 also present in the cytoplasm; apparently exclusively so at some developmental stages, i.e. gonocytes and late pachytene spermatocytes? While the functional significance of this is not known, we propose that it is either because RHOX10 is sequestered from functioning as a transcription factor at these developmental stages or because RHOX10 has a functional role in the cytoplasm at these stages. With regard to the former possibility, another homeobox transcription factor, PDX1, is restricted to the cytoplasm until glucose triggers its translocation into the nucleus, where it binds and activates the insulin gene promoter (Macfarlane et al. 1999). In support of the latter possibility, several homeobox transcription factors have been shown to regulate cytoplasmic events, including translation, through their ability to bind to RNA or RNAbinding proteins (Niessing et al. 2002, Cho et al. 2005). What biological activity might RHOX10 have in the cytoplasm of gonocytes? Given RHOX10's male-specific expression pattern in fetal germ cells (Daggag et al. 2008), we suggest that cytoplasmic RHOX10 might 
A

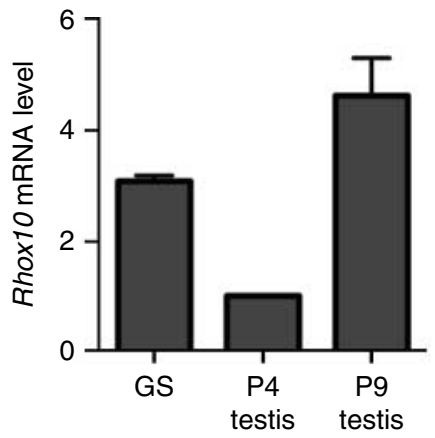

B

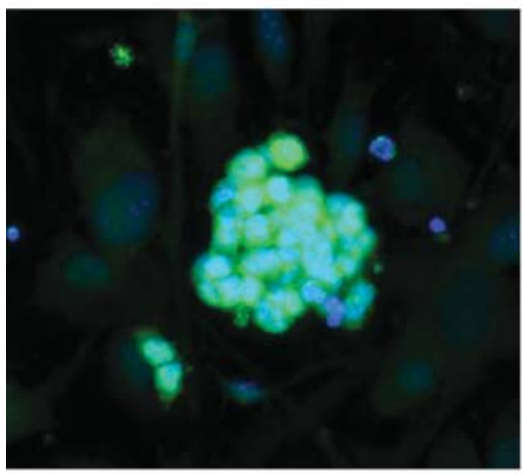

$\mathrm{RHOX} 10 \mathrm{Ab}$

C

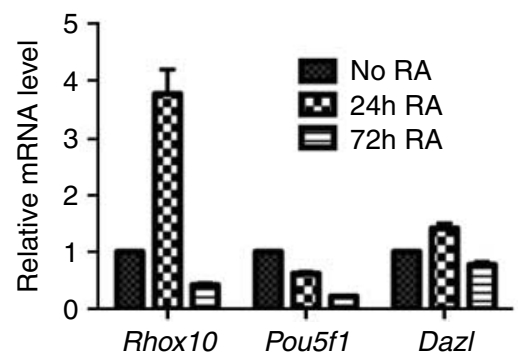

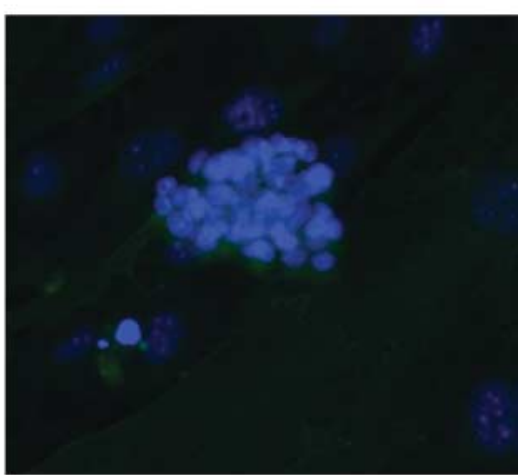

$\lg G$

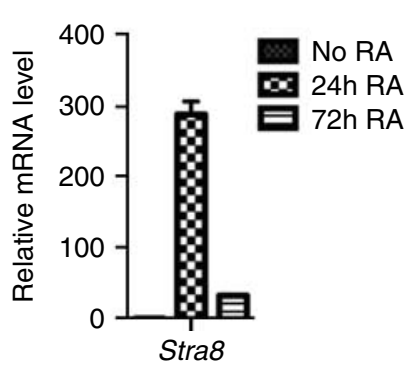

Figure 7 Expression and regulation of Rhox 10 in GS cells. (A) qRT-PCR analysis of Rhox 10 mRNA level in GS cells and postnatal testes, performed and quantified as in Fig. 1. The level of Rhox 10 mRNA in P4 testes was arbitrarily set to 1 . (B) Immunofluorescence analysis of RHOX10 protein expression in GS cells. Fixed GS cells were incubated with RHOX10 antiserum or IgG control serum, followed by a Alexa 488-labeled secondary antibody (green). DAPI was used for nuclear staining (blue). (C) qRTPCR analysis of the indicated mRNAs in GS cells treated with $1 \mu \mathrm{M}$ RA for the times indicated, performed and quantified as in Fig. 1. The level of each mRNA in untreated cells was arbitrarily set to 1 . participate in preventing gonocytes from entering meiosis, as only male fetal germ cells, not female fetal germ cells, avoid initiating meiosis until puberty (Lin et al. 2008). Cytoplasmic RHOX10 might also participate in the male-specific mitotic arrest that occurs as male germ cells undergo differentiation into gonocytes in the fetal testis (Culty 2009).

We observed a correlation between RHOX10 localization and the cell cycle status of cells. RHOX10 is exclusively in the cytoplasm of the mitotically arrested cells we examined (E15.5 gonocytes), whereas it is in both the nuclear and the cytoplasmic compartments of mitotic cells (spermatogonia and epididymal somatic cells). RHOX10 localization is also associated with the meiotic status of cells, as we found RHOX10 exclusively in the nucleus of early meiotic germ cells (leptotene to early pachytene spermatocytes). These shifts in RHOX10 subcellular localization could be the consequence of specific mitotic and meiotic signals that impinge on its nuclear-cytoplasmic transport and/or its binding to different DNA and RNA targets in the nucleus and cytoplasm, respectively, in a developmentally regulated manner. For example, RHOX10 in gonocytes may preferentially bind mRNA targets that hold RHOX10 in the cytoplasmic compartment, while RHOX10 in spermatocytes may preferentially bind DNA targets that retain RHOX10 in the nuclear compartment. It will be intriguing in the future to determine whether RHOX10 has distinct functions in these two subcellular locations to support different cellular events.

The finding that RHOX10 protein is undetectable in late germ cells (the diplotene spermatocyte stage and thereafter) is interesting in light of the relatively high levels of Rhox10 mRNA in these germ cell fractions 


\begin{tabular}{|c|c|c|c|c|c|c|c|c|c|c|c|c|c|}
\hline & \multirow{2}{*}{ Gonocytes } & \multicolumn{3}{|c|}{ Spermatogonia } & \multicolumn{6}{|c|}{ Spermatocytes } & \multicolumn{2}{|c|}{ Spermatids } & \multirow{2}{*}{$\begin{array}{c}\text { Epididymal } \\
\text { somatic } \\
\text { cells }\end{array}$} \\
\hline & & Undiff A & Diff A & Type-B & Prelep & Lep & Zyg & Early $\mathrm{P}$ & Late $\mathrm{P}$ & Dip & Round & Elong & \\
\hline Pre-mRNA ${ }^{a}$ & ND & & & & & & & & & & & & ND \\
\hline \multicolumn{14}{|l|}{$\mathrm{mRNA}^{\mathrm{a}}$} \\
\hline \multicolumn{14}{|l|}{ Protein $^{a}$} \\
\hline $\begin{array}{l}\text { Subcellular } \\
\text { localization }\end{array}$ & Cyto & & Nuc/Cyto & & & & & & Cyto & & NA & & Nuc/Cyto \\
\hline
\end{tabular}

Figure 8 Summary of Rhox10/RHOX10 expression and localization. Undiff A, undifferentiated type A spermatogonia; Diff A, differentiating type A spermatogonia; type B, type B spermatogonia; Prelep, preleptotene spermatocytes; Lep, leptotene spermatocytes; Zyg, zygotene spermatocytes; Early P, early pachytene spermatocytes; Late P, late pachytene spermatocytes; Dip, diplotene spermatocytes; Round, round spermatids; Elong, elongating spermatids; ND, not determined; NA, not available; Cyto, cytoplasm; Nuc, nucleus. ${ }^{\mathrm{a} C o l o r}$ intensity represents the level of expression. Diagonal lines indicate no detectable expression.

(A and 4). In particular, we found that Rhox10 mRNA levels were only three- to four-fold lower in the purified round and elongated spermatid fractions than in undifferentiated type A spermatogonia, the highest Rhox10-expressing germ cell subset (Fig. 3A). This suggests that either Rhox10 mRNA is translationally repressed after mid-meiosis or RHOX10 protein is destabilized during mid-meiosis. It is not known for what purpose Rhox10 mRNA is present in round spermatids and elongated spermatids. It is possible that Rhox10 mRNA is being stored, awaiting a signal to produce RHOX10 protein later when it might be required for spermatozoa maturation or fertilization. This would not be entirely surprising, as the translation of many transcripts has been shown to be subject to regulation at different points of development in both male and female germ cells (Hecht 1998). Indeed, recently it has been reported that a member of Rhox gene cluster, Rhox 13, is translationally repressed by the RNAbinding protein, NANOS2, in gonocytes and early spermatogonia (Geyer et al. 2011). However, unlike RHOX13, RHOX10 is not translationally repressed in gonocytes but instead is highly expressed in these cells (Fig. 6). Thus, clearly these two proteins must be differentially regulated by translation. In the case of RHOX10, our finding that the temporal expression of RHOX10 protein increases before Rhox10 mRNA does after birth (Fig. 1) suggests that it is subject to translational activation or release from translational repression during the transition from gonocytes to early spermatogonia.

Another unusual aspect of the regulation of Rhox10 that we uncovered is its apparent transcriptional repression very early during male germ cell development. We found that Rhox 10 pre-mRNA level is strongly reduced in late spermatogonia (Fig. 3B), well before $\mathrm{MSCl}$ triggers general transcriptional repression of $\mathrm{X}$-linked genes in pachytene spermatocytes. To our knowledge, transcriptional repression in late spermatogonia has not been demonstrated before for any other gene. This finding leads to the interesting question of how mature Rhox 10 mRNA is maintained at relatively high level in spermatocytes and spermatids given that Rhox 10 transcription is nearly completely shut down in these stages. It would appear that some mechanism is in place to stabilize Rhox10 mRNA during meiosis and spermatid maturation. Perhaps, this is to ensure that some RHOX10 protein is made at later stages because of functional roles RHOX10 has in these later stages.

RHOX10 has a reciprocal pattern of expression in the testis and the epididymis (Figs 4 and 5 respectively). In the former, it is specifically expressed in germ cells, whereas in the latter, it is only expressed in somatic cells. By analogy, many other developmentally regulated genes, including Rhox5, have been shown to be expressed in germ cells in one context and somatic cells in another context, i.e. in a different tissue or developmental stage (Eddy \& O'Brien 1998, Pitman et al. 1998). The region-specific expression pattern of RHOX10 in epididymis (Fig. 5) suggests the possibility that RHOX10 has a function in the caput. For example, RHOX10 might promote sperm maturation, as this is known to occur in the caput (Cosentino \& Cockett 1986, Jones 1999). We previously showed that another member of the Rhox gene cluster selectively expressed in the caput - Rhox 5 - promotes the acquisition of sperm forward motility (Rao et al. 2002, Maclean et al. 2005). This raises the possibility that RHOX5 and RHOX10 collaborate and/or act redundantly in this process, a possibility that is supported by our recent finding that RHOX 5 and RHOX10 regulate many of the same genes, albeit in transfected somatic cells (Hu et al. 2010).

Using GS cells as model system to study Rhox10 regulation, we discovered that RA upregulates Rhox10 expression in these cells (Fig. 7). Given that RA promotes meiotic initiation in both spermatogenesis and oogenesis (Lin et al. 2008), this implies that Rhox10 may be involved in the differentiation process that converts mitotic spermatogonia into meiotic spermatocytes. Consistent with this, our immunohistochemical analysis revealed that RHOX10 level peaks in early meiotic spermatocytes (preleptotene, leptotene, and zygotene spermatocytes; Fig. 4).

In conclusion, we have provided evidence that RHOX10 expression is regulated by a myriad of transcriptional and posttranscriptional mechanisms in male germ cells. Most prominently, we show that RHOX10 is in different subcellular compartments at different steps of germ cell development. While the 
Table 1 List of primers used for qRT-PCR.

\begin{tabular}{|c|c|c|c|c|}
\hline Gene & Sense & Antisense & Sense sequence & Antisense sequence \\
\hline Rhox 10 & MDA-3380 & MDA-3381 & GTGGACGAATGCAAGGT & TGGCACACAATGAACC \\
\hline Rhox 10 & MDA-1382 & MDA-1383 & AGAAGTACCCAATGCCCAAAT & TCGTCCACATCAATAAGTTTT \\
\hline Rhox 10 pre-mRNA & UCSD-6811 & UCSD-6812 & GATGCACACCAAAGGTGAGT & TGAAGAAGTAGGCACCAGGA \\
\hline Dazl & MDA-3628 & MDA-3629 & GACGTGGATGTGCAGAAGAT & GTGGTGGAGGAGGAGGATTA \\
\hline Stra8 & MDA-3787 & MDA-3788 & TCAACAACCTAAGGAAGGCA & TCCAGGCTTTCTTCCTGTTC \\
\hline Cst11 & MDA-4069 & MDA-4070 & CTTGAAGACAGAGACGAGCCT & TGAATACTTCAACCCAGGGAA \\
\hline Neurog3 & UCSD-6711 & UCSD-6712 & CCAAGAGCGAGTTGGCACT & CGGGCCATAGAAGCTGTGG \\
\hline Nanos2 & UCSD-5843 & UCSD-5844 & ACCGGCGACCAGGCTCATACA & AGTTTCGCCCACTGCGTCGG \\
\hline Tubb3 & UCSD-5303 & UCSD-5304 & СССССАGAGCСATCTAGСТАСТ & ACTTTAACCTGGGAGCCCTAATG \\
\hline Fmr1 & UCSD-6389 & UCSD-6390 & CСTGCAGAGTGCСTCCAGTGAAG & CAGCGGTTGCAGCCCATCTACG \\
\hline RPL19 & UCSD-4667 & UCSD-4668 & CTGAAGGTCAAAGGGAATGTG & GGACAGAGTCTTGATGATCTC \\
\hline
\end{tabular}

precise developmental functions of RHOX10 are not yet known, we showed that its expression in GS cells is regulated by RA, which indicates that RHOX10 is a good candidate to function as a transcription factor that maintains the fate of stem and/or progenitor germ cells.

\section{Materials and Methods}

\section{Animals}

Mouse colonies were maintained in agreement with protocols approved by the Institutional Animal Care and Use Committee at the University of California, San Diego. All animals were housed under a $12 \mathrm{~h}$ light:12 h darkness cycle and provided with food and water ad libitum. Castration was performed as described previously (Cornwall et al. 1992, Hsia \& Cornwall 2003).

\section{qRT-PCR analysis}

cDNAs were generated from 0.5 to $1 \mu \mathrm{g}$ total RNA using the Iscript reverse transcriptase (RT) kit, according to the manufacturer's protocol (Bio-Rad). Primer pairs were designed to amplify only spliced mRNA (by virtue of being complementary with sequences in separate exons; Table 1). Primer pair MDA3380/3381 were used to measure Rhox 10 mRNA levels, unless otherwise noted. The RT product and a set of primers were mixed with iQ SYBR Green supermix (Bio-Rad) and PCR was performed using a iCycler real-time PCR machine according to the manufacturer's protocol (Bio-Rad). The production of the amplicon was measured by SYBR green fluorescence and the threshold cycle $\left(C_{\mathrm{t}}\right)$ values were calculated. The $C_{\mathrm{t}}$ values obtained were normalized to that for the transcript encoding the ribosomal protein RPL19 (L19).

\section{Generation and purification of RHOX10 antiserum}

A GST-fusion protein containing RHOX10 protein sequences (amino acids 25-84) was generated in Escherichia coli from a Rhox 10 cDNA cloned into the expression vector pGEX4T-1 (GE Healthcare, Piscataway, NJ, USA). Two rabbits were immunized with this fusion protein and serum was collected at four time intervals by Proteintech Group, Inc. (Chicago, IL, USA). IgG purified from the final bleed using protein $G$ beads was used for western blot analysis and immunohistochemistry.

\section{Immunohistochemical analysis}

Embryonic, postnatal, and adult tissues were obtained from C57BL/6J mice. The embryonic age of fetal gonads was calculated according to the day on which a vaginal plug was observed. Tissues were fixed in 10\% neutral-buffered formalin immediately after dissection. After 1 to $6 \mathrm{~h}$ of fixation, they were dehydrated in a series of ethanol washes of different concentration and embedded in paraffin using standard procedures. Sections were deparaffinized two times in xylene, followed by serial dilutions of ethanol. The internal peroxidase activity was removed by incubation with $0.3 \%$ hydroperoxide in methanol for $15 \mathrm{~min}$. Sections were blocked by incubating with $3 \%$ serum (from the species that the secondary antibody was raised in) for $30 \mathrm{~min}$ at room temperature, followed by incubation overnight at room temperature with the following primary antisera: RHOX10 (1:300) and POU5F1 (1:200). After secondary antibody incubation for $1 \mathrm{~h}$ at room temperature, the peroxidase activity was detected using the Vectastain $A B C$ kit (Vector Laboratory, Inc., Burlingame, CA, USA), followed by addition of DAB solution. For adult tissue, nuclei were counterstained with hematoxylin. After dehydration, a coverslip was placed over the sections with mounting medium. The sections were viewed with a Leica DMI6000 B inverted microscope (Leica, Voorburg, The Netherlands).

\section{Immunofluorescence analysis}

GS cells grown in a 24-well plate were fixed with $4 \%$ paraformaldehyde for $15 \mathrm{~min}$, permeabilized in PBS containing $0.1 \%$ Triton X100 for $15 \mathrm{~min}$, blocked for $1 \mathrm{~h}$ in $5 \%$ goat serum at room temperature, incubated overnight at $4{ }^{\circ} \mathrm{C}$ with RHOX 10 antiserum or IgG-purified preimmune serum (diluted 1:300), washed, and incubated with anti-rabbit IgG-conjugated with Alexa 488 (diluted 1:500) for $1 \mathrm{~h}$ at room temperature. Counter staining was performed with DAPI. The images were viewed using a Leica DMI4000 B fluorescence microscope (Leica).

\section{GS cell culture}

GS cells (DGC1) were cultured as described previously (Dann et al. 2008, Falciatori et al. 2008). For RA induction, GS cells were plated at a density of $2.5 \times 10^{5} \mathrm{cell} / \mathrm{cm}^{2}$ onto plates with mouse embryo fibroblast feeder cells for $24 \mathrm{~h}$ followed by addition of RA ( $1 \mu \mathrm{M}$ final concentration). 


\section{Declaration of interest}

The authors declare that there is no conflict of interest that could be perceived as prejudicing the impartiality of the research reported.

\section{Funding}

This work was supported by the National Institutes of Health (R01-HD053808).

\section{Acknowledgements}

The authors thank YanHe Lue and Ronald S. Swerdloff (HarborUCLA) for generously providing testis samples from KS (XXY) mice. The authors also thank Karel De Gendt (UCSD) for helpful discussions.

\section{References}

Anderson EL, Baltus AE, Roepers-Gajadien HL, Hassold TJ, de Rooij DG, van Pelt AM \& Page DC 2008 Stra8 and its inducer, retinoic acid, regulate meiotic initiation in both spermatogenesis and oogenesis in mice. PNAS 105 14976-14980. (doi:10.1073/pnas.0807297105)

Bowles J, Knight D, Smith C, Wilhelm D, Richman J, Mamiya S, Yashiro K, Chawengsaksophak K, Wilson MJ, Rossant J et al. 2006 Retinoid signaling determines germ cell fate in mice. Science 312 596-600. (doi:10.1126/science.1125691)

Chan WK, Bhalla AD, Le Hir H, Nguyen LS, Huang L, Gecz J \& Wilkinson MF 2009 A UPF3-mediated regulatory switch that maintains RNA surveillance. Nature Structural \& Molecular Biology 16 747-753. (doi:10.1038/nsmb.1612)

Cho PF, Poulin F, Cho-Park YA, Cho-Park IB, Chicoine JD, Lasko P \& Sonenberg N 2005 A new paradigm for translational control: inhibition via $5^{\prime}-3^{\prime}$ mRNA tethering by Bicoid and the elF4E cognate 4EHP. Cell 121 411-423. (doi:10.1016/j.cell.2005.02.024)

Cornwall GA 2009 New insights into epididymal biology and function. Human Reproduction Update 15 213-227. (doi:10.1093/humupd/ dmn055)

Cornwall GA, Orgebin-Crist MC \& Hann SR 1992 The CRES gene: a unique testis-regulated gene related to the cystatin family is highly restricted in its expression to the proximal region of the mouse epididymis. Molecular Endocrinology 6 1653-1664. (doi:10.1210/me.6.10.1653)

Cosentino MJ \& Cockett AT 1986 Structure and function of the epididymis. Urological Research 14 229-240. (doi:10.1007/BF00256565)

Culty M 2009 Gonocytes, the forgotten cells of the germ cell lineage. Birth Defects Research. Part C, Embryo Today: Reviews 87 1-26. (doi:10.1002/ bdrc.20142)

Daggag $H$, Svingen T, Western PS, van den Bergen JA, McClive PJ, Harley VR, Koopman P \& Sinclair AH 2008 The rhox homeobox gene family shows sexually dimorphic and dynamic expression during mouse embryonic gonad development. Biology of Reproduction 79 468-474. (doi:10.1095/biolreprod.107.067348)

Dai T, Vera Y, Salido EC \& Yen PH 2001 Characterization of the mouse Dazap1 gene encoding an RNA-binding protein that interacts with infertility factors DAZ and DAZL. BMC Genomics 2 6. (doi:10.1186/1471-2164-2-6)

Dann CT, Alvarado AL, Molyneux LA, Denard BS, Garbers DL \& Porteus MH 2008 Spermatogonial stem cell self-renewal requires OCT4, a factor downregulated during retinoic acid-induced differentiation. Stem Cells 26 2928-2937. (doi:10.1634/stemcells.2008-0134)

Eddy EM \& O'Brien DA 1998 Gene expression during mammalian meiosis. Current Topics in Developmental Biology 37 141-200. (doi:10.1016/ S0070-2153(08)60174-X)

Falciatori I, Lillard-Wetherell K, Wu Z, Hamra FK \& Garbers DL 2008 Deriving mouse spermatogonial stem cell lines. Methods in Molecular Biology 450 181-192.
Geyer CB \& Eddy EM 2008 Identification and characterization of Rhox13, a novel X-linked mouse homeobox gene. Gene 423 194-200. (doi:10.1016/j.gene.2008.06.031)

Geyer CB, Saba R, Kato Y, Anderson AJ, Chappell VK, Saga Y \& Eddy EM 2011 Rhox13 is translated in premeiotic germ cells in male and female mice and is regulated by NANOS2 in the male. Biology of Reproduction. [in press]. (doi:10.1095/biolreprod.111.094938)

Griswold MD, Hogarth CA, Bowles J \& Koopman P 2012 Initiating meiosis: the case for retinoic acid. Biology of Reproduction 86 35. (doi:10.1095/ biolreprod.111.096610)

Hecht NB 1998 Molecular mechanisms of male germ cell differentiation. Bioessays 20 555-561. (doi:10.1002/(SICI)1521-1878(199807)20:7< 555::AID-BIES6 > 3.0.CO;2-J)

Hsia N \& Cornwall GA 2003 Cres2 and Cres3: new members of the cystatin-related epididymal spermatogenic subgroup of family 2 cystatins. Endocrinology 144 909-915. (doi:10.1210/en.2002-220890)

Hu Z, Dandekar D, O'Shaughnessy PJ, De Gendt K, Verhoeven G \& Wilkinson MF 2010 Androgen-induced Rhox homeobox genes modulate the expression of AR-regulated genes. Molecular Endocrinology 24 60-75. (doi:10.1210/me.2009-0303)

Huang L, Lou CH, Chan W, Shum EY, Shao A, Stone E, Karam R, Song HW \& Wilkinson MF 2011 RNA homeostasis governed by cell type-specific and branched feedback loops acting on NMD. Molecular Cell 43 950-961. (doi:10.1016/j.molcel.2011.06.031)

Imam JS, Gudikote JP, Chan WK \& Wilkinson MF 2009 Frame-disrupting mutations elicit pre-mRNA accumulation independently of frame disruption. Nucleic Acids Research 38 1559-1574. (doi:10.1093/nar/gkp1115)

Jones RC 1999 To store or mature spermatozoa? The primary role of the epididymis International Journal of Andrology 22 57-67. (doi:10.1046/j. 1365-2605.1999.00151.x)

Kanatsu-Shinohara M \& Shinohara T 2007 Culture and genetic modification of mouse germline stem cells. Annals of the New York Academy of Sciences 1120 59-71. (doi:10.1196/annals.1411.001)

Krumlauf R 1994 Hox genes in vertebrate development. Cell 78 191-201. (doi:10.1016/0092-8674(94)90290-9)

Kubota H, Avarbock MR \& Brinster RL 2004 Culture conditions and single growth factors affect fate determination of mouse spermatogonial stem cells. Biology of Reproduction 71 722-731. (doi:10.1095/biolreprod. 104.029207)

Lin Y, Gill ME, Koubova J \& Page DC 2008 Germ cell-intrinsic and -extrinsic factors govern meiotic initiation in mouse embryos. Science $\mathbf{3 2 2}$ 1685-1687. (doi:10.1126/science.1166340)

Lindsey JS \& Wilkinson MF 1996 Pem: a testosterone- and LH-regulated homeobox gene expressed in mouse Sertoli cells and epididymis. Developmental Biology 179 471-484. (doi:10.1006/dbio.1996.0276)

Macfarlane WM, McKinnon CM, Felton-Edkins ZA, Cragg H, James RF \& Docherty K 1999 Glucose stimulates translocation of the homeodomain transcription factor PDX1 from the cytoplasm to the nucleus in pancreatic beta-cells. Journal of Biological Chemistry 274 1011-1016. (doi:10.1074/jbc.274.2.1011)

MacLean JA II \& Wilkinson MF 2010 The Rhox genes. Reproduction 140 195-213. (doi:10.1530/REP-10-0100)

MacLean JA II, Chen MA, Wayne CM, Bruce SR, Rao M, Meistrich ML, Macleod C \& Wilkinson MF 2005 Rhox: a new homeobox gene cluster. Cell 120 369-382. (doi:10.1016/j.cell.2004.12.022)

MacLean JA II \& Wilkinson MF 2005 Gene regulation in spermatogenesis. Curr Top Dev Biol 71 131-197. (doi:10.1016/S0070-2153(05)71005-X)

McGinnis W \& Krumlauf R 1992 Homeobox genes and axial patterning. Cell 68 283-302. (doi:10.1016/0092-8674(92)90471-N)

Mueller JL, Mahadevaiah SK, Park PJ, Warburton PE, Page DC \& Turner JM 2008 The mouse $\mathrm{X}$ chromosome is enriched for multicopy testis genes showing postmeiotic expression. Nature Genetics 40 794-799. (doi:10.1038/ng.126)

Niessing D, Blanke S \& Jackle H 2002 Bicoid associates with the $5^{\prime}$-capbound complex of caudal mRNA and represses translation. Genes and Development 16 2576-2582. (doi:10.1101/gad.240002)

Panganiban G \& Rubenstein JL 2002 Developmental functions of the distal-less/Dlx homeobox genes. Development 129 4371-4386.

Pearson JC, Lemons D \& McGinnis W 2005 Modulating Hox gene functions during animal body patterning. Nature Reviews. Genetics 6 893-904. (doi:10.1038/nrg1726) 
Pitman JL, Lin TP, Kleeman JE, Erickson GF \& MacLeod CL 1998 Normal reproductive and macrophage function in Pem homeobox gene-deficient mice. Developmental Biology 202 196-214. (doi:10.1006/dbio.1998.8978)

Rao MK, Wayne CM \& Wilkinson MF 2002 Pem homeobox gene regulatory sequences that direct androgen-dependent developmentally regulated gene expression in different subregions of the epididymis. Journal of Biological Chemistry 277 48771-48778. (doi:10.1074/jbc.M209417200)

Rao MK, Wayne CM, Meistrich ML \& Wilkinson MF 2003 Pem homeobox gene promoter sequences that direct transcription in a Sertoli cell-specific, stage-specific, and androgen-dependent manner in the testis in vivo. Molecular Endocrinology 17 223-233. (doi:10.1210/me.2002-0232)

de Rooij DG, Okabe M \& Nishimune Y 1999 Arrest of spermatogonial differentiation in jsd/jsd, SI17H/SI17H, and cryptorchid mice. Biology of Reproduction 61 842-847. (doi:10.1095/biolreprod61.3.842)

Song R, Ro S, Michaels JD, Park C, McCarrey JR \& Yan W 2009 Many X-linked microRNAs escape meiotic sex chromosome inactivation. Nature Genetics 41 488-493. (doi:10.1038/ng.338)

Swerdloff RS, Lue Y, Liu PY, Erkkila K \& Wang C 2011 Mouse model for men with klinefelter syndrome: a multifaceted fit for a complex disorder. Acta Paediatrica 100 892-899. (doi:10.1111/j.1651-2227.2011.02149.x)

Tedesco M, La Sala G, Barbagallo F, De Felici M \& Farini D 2009 STRA8 shuttles between nucleus and cytoplasm and displays transcriptional activity. Journal of Biological Chemistry 284 35781-35793. (doi:10.1074/jbc.M109.056481)

Turner JM 2007 Meiotic sex chromosome inactivation. Development 134 1823-1831. (doi:10.1242/dev.000018)

Turner TT, Bomgardner D, Jacobs JP \& Nguyen QA 2003 Association of segmentation of the epididymal interstitium with segmented tubule function in rats and mice. Reproduction 125 871-878. (doi:10.1530/rep. $0.1250871)$
Wang PJ, McCarrey JR, Yang F \& Page DC 2001 An abundance of X-linked genes expressed in spermatogonia. Nature Genetics 27 422-426. (doi:10.1038/86927)

Yang F, Gell K, van der Heijden GW, Eckardt S, Leu NA, Page DC, Benavente R, Her C, Hoog C, McLaughlin KJ et al. 2008 Meiotic failure in male mice lacking an X-linked factor. Genes and Development 22 682-691. (doi:10.1101/gad.1613608)

Yoshioka H, Geyer CB, Hornecker JL, Patel KT \& McCarrey JR 2007 In vivo analysis of developmentally and evolutionarily dynamic protein-DNA interactions regulating transcription of the Pgk2 gene during mammalian spermatogenesis. Molecular and Cellular Biology 27 7871-7885. (doi:10.1128/MCB.00990-07)

Zhang L, Zhou W, Velculescu VE, Kern SE, Hruban RH, Hamilton SR, Vogelstein B \& Kinzler KW 1997 Gene expression profiles in normal and cancer cells. Science 276 1268-1272. (doi:10.1126/science.276.5316. 1268)

Zhang Z, Shao S \& Meistrich ML 2006 Irradiated mouse testes efficiently support spermatogenesis derived from donor germ cells of mice and rats. Journal of Andrology 27 365-375. (doi:10.2164/jandrol.05179)

Zheng K, Yang F \& Wang PJ 2010 Regulation of male fertility by X-linked genes. Journal of Andrology 31 79-85. (doi:10.2164/jandrol.109. 008193)

Received 16 December 2011

First decision 17 January 2012

Revised manuscript received 25 February 2012

Accepted 2 March 2012 